\title{
Straight talk from... Ashok Alexander
}

India surprised the world when it announced in July that, far from being the nation with the most cases of HIV/AIDS, it is home to 2.5 million infected individuals - fewer than half of the previous estimate. The government insists that the new figures, which are supported by UNAIDS, result from a radically improved surveillance system, a national family health survey that for the first time included HIV blood tests, and a change in the way data are analyzed. Still, India lags only South Africa and Nigeria in the size of its AIDS burden. Ashok Alexander, director of Avahan, the Bill \& Melinda Gates Foundation's Indian initiative on AIDS, and one of the survey's sponsors, explains why the dramatically lower numbers are no reason to celebrate.

What does the new estimate mean for India's AIDS epidemic? At one level, this is obviously good news. But on another level, nothing has changed, as far as we're concerned. Our epidemic kills several hundred thousand Indians every year. It destabilizes large populations. I'd still use the word 'crisis' to describe it.

The numbers are half of what they were. Do you think that's believable? I suspect the real number of HIV/AIDS cases will actually lie somewhere between the previous estimate and the new one. I think these studies are as much art as science. The thing is to not get too elated or too depressed by it, and to simply keep looking at trends. We now have the first dot on the graph, but you usually need at least three dots to make a trend, so it'll be six or seven years before we get anything useful.

But every time new numbers come out, there will be a bit of an upheaval. With this study, the total sample size could have been larger, for example. A sample size of 102,000 has been extrapolated for India as a whole. Prabhat Jha, an epidemiologist at the University of Toronto, is coming up with a study that has a cohort of 10 million. We at Avahan are also planning to release data from the first systematic survey of highrisk groups in India, with a sample size of 25,000 . I suspect that this controversy about numbers has not ended, it's just begun.

What are some new trends that are surfacing in the Indian epidemic? One positive thing is that we now have evidence that prevention can actually work. This is not a minor statement, because there are a lot of people around the world who question whether HIV prevention works. For example, in Tamil Nadu state, it started at about 1.5 percent prevalence and has now come down to under 0.5 percent over a decade. Early data is very encouraging, that after just a few years of early prevention we're seeing some impact. But the challenge is to do prevention at scale.

There are a growing number of rural infections. There is also an increasing feminization of the epidemic. This is a trend that occurs when an epidemic matures: earlier it's mainly male infections, and then men go home and pass it to their wives.

Another worrying trend is the emergence of high-risk groups that were previously not recognized. The large population of men having sex with men (MSM) and the transgenders are very often married, and their sexual practices are particularly risky. The MSM group was not even mentioned as a risk group in the national program until recently. We pretended that we did not even have this phenomenon! But it's a very large number.

What about hidden pockets of infection, such as housewives who secretly practice commercial sex?

This hidden nature of sex work is unique to the Indian epidemic. Unlike other countries where you have large red light areas, here-other than in the big cities-you'll never know who's a sex worker. Less than ten percent of sex work is brothel-based work; the rest of it is home-based or street-based. Often these are the women who don't come into the ambit of prevention services. I've met many housewives who practice commercial sex, and some of them give very simple reasons: we need the money, my daughter's in college, my son needs a personal computer.

The second unique thing about India is the extreme mobility of highrisk groups. The sex worker you work with today may be 2,000 kilometers away tomorrow. That makes them a moving invisible target.

Do you worry that the new numbers will make the government more complacent?

The good news is that the government has allocated almost $\$ 2.9$ billion for HIV/AIDS until 2012, which is many times what it was in the past. So I'm not worried, at least not for the next five years. But I would say the Indian epidemic has gone from terribly underfunded to, arguably, still underfunded.

India started at 11 cents per adult. The new amount works out to a little over a dollar for every adult, but even with this increase, Cambodia is still spending six times as much as us. Thailand is spending twice what we are spending per capita. China, with an infected population of 650,000, is spending colossal amounts of money. Luckily nowhere have governments said that the epidemic was over and that they would stop looking at it.

I am more worried about other things, which is that this is probably the most stigmatized health condition. It's the kind of stigma that makes a person disown his own child and do other unspeakable things that we read about in the papers, like people being stoned to death, children being denied education. You know, my own friends don't want me to talk about this; it's not the sort of subject that makes for scintillating talk at a cocktail party. I think that means that we have to step up our advocacy efforts to tell people, "Pay attention, it can affect you too."

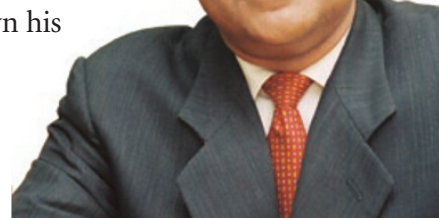

Are there organizations that should be stepping up to fight the epidemic, but aren't?

I would say the whole corporate community sector and Indian business could be very much more involved. Business supply chains could be used for transmitting AIDS messaging right to the rural areas and for condom distribution. Business leaders who have great stature in our country, who are more respected than even politicians, could also speak out. None of the above is happening.

The second group that can matter a hell of a lot is Indians living abroad. People who are sitting in the US with vast wealth and tremendous other resources such as business acumen, financial acumen, influence-we are hoping to get a few of those people involved, adopting districts, adopting their home ground in India and so on. The media could also be better informed about what the real issues are. I'm used to meeting journalists who know nothing.

Paroma Basu, New Delhi 